\title{
PREÇOS DOS IMÓVEIS EM NATAL-RN: BOLHA E CONTANGO NO PERÍODO 2005-2010
}

\author{
Márcia Maria de O. Bezerra ${ }^{1}$ \\ André Luíz Correa ${ }^{2}$ \\ Ana Rosa Ribeiro de Mendonça ${ }^{3}$ \\ Maria do Livramento Miranda Clementino ${ }^{4}$
}

RESUMO: À luz da abordagem de Davidson, a dinâmica de preços dos imóveis em Natal comporta fenômenos que merecem ser tratados. No período 2005-2007, observase uma situação de backwardation, cuja intensidade fornece evidências suficientes da ocorrência de uma bolha imobiliária na cidade. Após 2008, é possível identificar uma situação de contango diferente, percepção esta reforçada pelo movimento dos outros indicadores considerados na pesquisa referentes à comparação entre a evolução do valor dos aluguéis e a trajetória dos preços dos imóveis e à evolução do indicador de preço e custo da construção. Esse artigo explora a possibilidade do tipo de contango observado permitir que o tratamento de bolhas, sustentado na perspectiva teórica desenvolvida por Davidson, capte o ponto de inflexão desse fenômeno, ou seja, da possível passagem do movimento ascendente de preços em direção ao seu processo de arrefecimento.

Palavras-Chave: Bolha imobiliária. Capital estrangeiro. Crédito imobiliário

\footnotetext{
${ }^{1}$ Professora-Doutora do Departamento de Economia da Universidade Federal do Rio Grande do Norte (UFRN)

${ }^{2}$ Professor-Doutor da Universidade Estadual Paulista (UNESP)

${ }^{3}$ Professora-Doutora do Instituto de Economia da Universidade Estadual de Campinas (Unicamp)

${ }^{4}$ Professora-Doutora do Departamento de Políticas Públicas da UFRN
} 


\section{INTRODUÇÃO}

Carvalho (1996) ao tratar da importância da teoria da preferência pela liquidez na macroeconomia pós-keynesiana observa que o modelo apresentado no capítulo 17 , da Teoria Geral, teve avanços importantes a partir das reflexões de alguns autores, citando com destaque a obra de Davidson (1972, cap. 4). Em sua perspectiva, este último autor teria formulado "uma teoria keynesiana do investimento que se apoia no modelo de precificação de ativos" (CARVALHO, 1996, p. 60)

$\mathrm{Na}$ verdade, uma versão anterior desse tratamento pode ser encontrada no artigo Money, portfolio balance, capital accumulation, and economic growth, publicado na Econometrica (1968) Mas realmente é na obra de 1978, no capítulo "The demand and supply of capital goods - the Building blocks of a theory of accumulation", que Davidson examina de forma pormenorizada as diversas fases da acumulação de capital, incluindo as situações de backwardation em que o investimento líquido é positivo (ou zero) e as situações de contango, nas quais há redundância de capital.

Davidson (1994), porém, observa que seu modelo tem por base o Tratado sobre a Moeda (1930) e ele utiliza, inclusive, a linguagem de mercado (backwardation e contango) adotada por Keynes na aludida obra. Contudo, esclarece que seu modelo foi desenvolvido em Davidson (1968) e Davidson (1972).

Embora o tratamento desenvolvido por Davidson seja voltado para as decisões de investimento e seus impactos sobre a taxa de acumulação de capital, o mesmo pode, a partir de algumas adaptações, ser aplicado à análise do mercado imobiliário. Uma evidência empírica dessa possibilidade é dada pela análise sobre a dinâmica de preços no mercado imobiliário de Natal, cidade turística do Nordeste brasileiro, no período 2005-2010, efetuada por Bezerra et al. (2013).

Contando com cerca de oitocentos mil habitantes, Natal recebia nesse período aproximadamente dois milhões de visitantes domésticos e estrangeiros, notadamente europeus. Por dispor de um razoável aporte de infraestrutura em termos de rede hoteleira e gastronomia, a capital do Rio Grande do Norte foi escolhida para ser uma das cidades-sede da Copa do Mundo de Futebol de 2014, realizada no Brasil. 
A atração de turistas estrangeiros e brasileiros contribuiu para aquecer o mercado de imóveis da cidade, suscitando um movimento de preços no período acima aludido, cujo tratamento analítico foi inspirado nas visões de Keynes (1936), Davidson (1978/1982) e Dymski (1998), e baseado nas seguintes hipóteses:

a) o aquecimento dos mercados primários e secundários de imóveis residenciais de construção vertical na cidade no período 2005-2007 configuraria, tipicamente, uma situação de bolha imobiliária; b) no biênio seguinte 2009-2010, após a crise financeira de 2008, o movimento de alta de preços teria se mantido, tanto no caso dos imóveis na planta ${ }^{5}$ quanto dos imóveis prontos negociados no mercado secundário. (BEZERRA et all, 2013, p. 169)

Os indicadores levantados na referida pesquisa permitiram a coleta de evidências suficientes para ampliar o grau de confiança na hipótese de que ocorreu um ciclo expansivo de alta intensidade no mercado de imóveis da cidade, no triênio 20052007. Contudo, após a crise financeira de 2008, observou-se que, embora os preços dos imóveis na planta (que iriam ou estavam sendo construídos) e dos imóveis prontos continuassem a subir no biênio 2009-2010, havia uma nítida mudança nos preços relativos dos mesmos quando comparados ao triênio anterior.

O principal indicador adotado para captar a evolução dos preços dos mercados de imóveis dessa cidade brasileira foi inspirado no trabalho de Davidson (1978/1982), o que envolveu a necessária adaptação do modelo à análise do setor imobiliário local e a consequente investigação da estrutura de preços relativos dos mercados spot e forward que geram as situações de backwardation e contango. No caso de Natal, os resultados obtidos a partir da pesquisa revelaram para os dois últimos anos da série, 2009-2010, uma situação de contango diferente das explicitadas por Davidson na aludida obra. Outros indicadores considerados na pesquisa reforçaram a constatação desse fenômeno novo.

A partir das evidências empíricas, este artigo explora as possibilidades: i) do modelo de Davidson ser passível de adaptação para o tratamento de um ciclo expansivo imobiliário, que no limite pode levar à formação de bolhas; e ii) do novo tipo

${ }^{5} \mathrm{O}$ lançamento dos imóveis na planta corresponde a uma proxy do mercado forward, considerando que a cidade não dispõe de um mercado futuro organizado para imóveis. O comprador do imóvel tem a opção de comprar o imóvel tão logo comece o processo de edificação, financiando com o pagamento de suas prestações a construção do imóvel. 
de contango descoberto na cidade de Natal captar o ponto de inflexão desse ciclo, ou seja, da possível passagem do movimento ascendente de preços em direção ao seu processo de arrefecimento.

\section{O TRATAMENTO TEÓRICO DE BOLHAS DE ATIVO}

O movimento de preços dos imóveis em Natal no período 2005-2007 aconteceu concomitantemente ao influxo de capital estrangeiro - sobretudo para aplicação nos setores de turismo e imobiliário - e pela expansão do crédito imobiliário. O primeiro aspecto explica-se pelo movimento especulativo com imóveis na última década não ter ficado restrito aos Estados Unidos, mas ter se estendido a outros países centrais e incorporado em maior ou menor grau países em desenvolvimento ${ }^{6}$.

Bezerra et all (2013, P. 169) observam que em alguns desses países, o surgimento do boom imobiliário "manteve estreita conexão com negócios turísticos", provocada, sobretudo, "pelo elevado índice de construção de novos empreendimentos, cujo público-alvo era os turistas estrangeiros". "Muitos desses turistas combinavam interesses de aplicação de riqueza com o de constituir uma segunda residência nessas destinações". "O litoral do estado do Rio Grande do Norte, no Nordeste brasileiro, notadamente sua capital, Natal, atraiu diversos visitantes procedentes em sua grande maioria de países europeus que realizaram este propósito, o que contribuiu para aquecer fortemente o mercado de imóveis local." Informações de agentes do setor imobiliário da cidade revelavam que cerca de $40 \%$ da demanda por apartamentos no período 2005-2007 era proveniente de estrangeiros. Tal demanda levou alguns especuladores desses países a comprarem vários apartamentos na cidade com o propósito de revendê-los a seus concidadãos. ${ }^{7}$

As evidências pareciam apontar para a formação de uma bolha desse ativo, pois como observa Dymski (1998, 2004), uma das características desse fenômeno é que

\footnotetext{
${ }^{6} \mathrm{~A}$ propagação desse fenômeno em escala mundial foi sustentada em parte pela elevada liquidez internacional, alimentada pela política monetária americana que manteve baixas taxas de juros durante grande parte do período, e pela redução das barreiras à mobilidade de capitais, ensejada pelos processos de desregulamentação e abertura financeira observados em vários países.

'Em reportagem publicada no Jornal Tribuna do Norte, de 18/08/2007, é feita menção ao período de auge da demanda estrangeira no bairro que concentra a oferta hoteleira da cidade, portugueses, noruegueses, italianos e espanhóis se dispunham a comprar os imóveis a ser lançados que asseguravam aos incorporadores rentabilidade acima de $40 \%$.
} 
sua ocorrência se dá em um determinado espaço, em uma "economia limitada por fronteira" ${ }^{\prime \prime}$. Ademais, nos aludidos trabalhos, esse autor chamava atenção para um aspecto que poderia contribuir para explicar a emergência da aludida bolha na cidade, qual seja, a absorção de fluxos de riqueza (internos ou internacionais) e/ou população, capazes de gerar uma pressão sobre os preços dos ativos comparativamente aos seus custos reais de produção. Ademais, com base em Minsky caberia considerar a evolução do ciclo de crédito no período, uma vez que as edificações têm preços suficientemente elevados que tornam sua oferta e demanda sensíveis às condições de financiamento (BEZERRA et al, 2013)

A pesquisa empírica foi sustentada à luz de teorias que, a partir das mediações necessárias ao tratamento das especificidades brasileiras e locais, serviram de orientação à montagem de indicadores capazes de aferir a evolução dos preços do mercado de imóveis na cidade, bem como ao seu exame. Neste sentido cabe destacar as obras de Keynes (1936), notadamente o capítulo 17 da Teoria Geral, e Davidson (1978/1982).

Com relação a Keynes, o referido capítulo é suficientemente fecundo para permitir que o tratamento de bolhas possa ser pensado mesmo no contexto de equilíbrio ${ }^{9}$, "desde que seja introduzida uma hipótese adicional que pressupõe o surgimento de um mecanismo de retroalimentação entre o atributo "a" e o preço do ativo. A condição para que haja bolha é que a expectativa de valorização, medida por esse atributo, responda ao aumento do preço corrente". E ainda, "pode-se supor, adicionalmente, que o consequente incremento nos preços alimente expectativas de novos aumentos", elevando os preços futuros esperados. "O conceito adequado para medir a intensidade da realimentação das expectativas sobre os preços é o de elasticidade das expectativas de Hicks (1939) (BEZERRA et al, 2013, p. 171).

\footnotetext{
${ }^{8}$ Para Dymski (2004: 412) "o termo é propositadamente elástico: um país é uma economia limitada por fronteiras, mas também o é uma cidade desse país, um bairro dessa cidade, uma rua desse bairro e até uma casa dessa rua".

${ }^{9}$ Keynes explica que a demanda por cada classe de ativo tem por base a consideração dos seguintes atributos: a geração de renda que sua posse pode proporcionar (lucros, juros, dividendos, aluguéis etc.), q; o custo de manutenção esperado associado à retenção do ativo, c; o prêmio de liquidez, l; e a apreciação ou depreciação esperada em seus valores de mercado, a. E todos eles seriam "medidos por um quociente em que o denominador é o preço spot corrente do ativo". Desse modo, a taxa de retorno esperada de cada ativo seria dada por a + q-c + I. (CARVALHO, 2007, p. 5-6)
} 
Os citados autores observam que "em sua estrutura analítica, Davidson (1972/1982) oferece indicações interessantes para se pensar" o caso de bolhas imobiliárias. "Este autor analisou em profundidade os componentes do atributo "a", identificando a partir de suas variáveis, preços forward e preço spot, mecanismos indutores das decisões de aplicação dos agentes". Na verdade, ele "construiu uma teoria a respeito de como o funcionamento dos mercados spot e forward afetam as decisões dos agentes e, por consequência, o desempenho da economia por meio de seus respectivos preços." Em sua perspectiva, "existe mercado spot quando seu preço correspondente permite alocar o estoque de uma mercadoria disponível, resultante de períodos de produção anteriores, de modo que não haja excesso de oferta e de demanda. No mercado forward deve haver alteração na quantidade produzida de um bem para entrega futura, com vista a atender os termos dos contratos celebrados com os seus compradores; o preço forward também pode ser visto como o preço do fluxo de oferta do período curto"10 (BEZERRA et al, 2013, p. 171).

Com base em Davidson, é possível constatar que os imóveis negociados em grandes áreas urbanas atendem aos requisitos para desenvolvimento dos mercados spot e forward"1, pois constituem "bens duráveis", cujo fluxo de produção em determinado período representa parcela pouco expressiva do total de estoque de imóveis existentes. Ademais,

(...) os arranjos institucionais sobre os quais se assentam as condições de oferta e demanda são de molde a garantir a existência dos dois mercados: as operações de incorporação, com a conseqüente contratação das atividades de construção civil representam o espaço institucional para o estabelecimento de uma proxy de mercado forward. Enquanto as empresas imobiliárias que operam como um canal de distribuição, ao atuarem na venda de lançamentos imobiliários (venda de imóveis na planta) e na comercialização de imóveis no

\footnotetext{
${ }^{10}$ Período curto "é a unidade de tempo relevante a valorização do capital", compreendendo o período de produção mais o período de mercado. Macedo e Silva (1999: P.77)

${ }^{11}$ Para que um ativo apresente mercados spot e forward bem organizados, que incluiriam: i) ter ampla demanda; ii) ser padronizado; iii) apresentar um elevado grau de substitutibilidade "entre velhos e novos itens"; iv) ter um fluxo anual de oferta pequeno quando comparado ao volume de estoque existente; v) ser durável; vi) e "ser valorizado em proporção ao seu volume". Observa, contudo, que o desenvolvimento dos mercados spot e forward está condicionado à existência das seguintes características: o fluxo anual de produção representar uma pequena proporção do estoque de bens existentes e desse bem ser durável. As demais seriam condições essenciais para que esses mercados se tornassem bem organizados e perfeitos, incluindo a existência de uma instituição que operasse como comprador e vendedor residual no mercado. (DAVIDSON, 1978, p. 94).
} 
mercado secundário (imóveis de terceiros), contribuem para aprofundar tais mercados, inclusive por prestarem serviços de locação (BEZERRA et al, 2013, P. 175).

Desse modo, o modelo de Davidson permite que as bolhas possam ser mostradas por meio do comportamento dos preços relativos (spot e forward), que reflete a interação entre oferta e demanda dos ativos imobiliários negociados nos respectivos mercados. Para tanto, é necessário fazer algumas adaptações, tais como:

a relação de preços a ser considerada deve ser preço do imóvel à vista (preço spot) nos mercados primários e preço do imóvel na planta. A inexistência de mercado futuro organizado para imóveis na cidade pode ser superada, para efeito de análise, pela suposição de ser o lançamento do próprio imóvel na planta uma proxy do mercado forward. Com relação à questão da heterogeneidade do ativo imobiliário, uma forma de contorná-la é considerar a produção de imóveis com características relativamente próximas, a exemplo da construção de imóveis verticais, cuja padronização mínima pode ser considerada quando se leva em conta a área construída e o bairro no qual o mesmo se localiza (BEZERRA, et al, 2013, p. 176).

Com base nessas considerações, os autores empregando a terminologia usada por Keynes e Davidson consideraram que uma situação de backwardation ocorreria quando o preço do imóvel à vista fosse mais elevado que o preço do imóvel na planta, o que tenderia a estimular sua produção para entrega a vista. Chamavam a atenção, em particular, para o caso em que essa diferença fosse muito elevada, pois a mesma indicaria a ocorrência de uma bolha imobiliária. A perspectiva inversa, preço do imóvel na planta mais caro que o imóvel pronto, configuraria uma situação de contango, que poderia ser gerada tanto por crises, quanto pela própria constatação de esgotamento da alta especulativa. O estouro de uma bolha imobiliária poderia gerar tal situação, desestimulando a produção de novos imóveis.

A crise de 2008, que afetou severamente os países emissores de turistas para o estado contribuiu para a redução do fluxo de capitais estrangeiros para aplicação no mercado imobiliário de Natal. Em 2009, o influxo de recursos estrangeiros para o setor turístico-imobiliário correspondeu a $26 \%$ do ano anterior, enquanto em 2010 , esse porcentual foi de cerca de 34\% do valor correspondente a 2008. Todavia, o movimento dos agentes domésticos foi distinto: a política contra-cíclica implementada pelos bancos públicos federais compensou a redução da oferta de crédito privado, o que resultou no aumento do financiamento imobiliário no período (a evolução do crédito total no Brasil 
no período $2008-2010$ foi de $27 \%$, enquanto no segmento crédito habitacional esse incremento foi em torno de $100 \%)^{12}$.

No próximo item será mostrada a evolução dos indicadores dos preços dos imóveis em Natal elaborados por Bezerra et al (2013) para aferir a dinâmica do setor no período 2005-2010.

\section{INDICADORES PARA CAPTAR A EVOLUÇÃO DOS PREÇOS DOS IMÓVEIS}

A variável mais significativa para se aferir a existência de uma bolha especulativa é a evolução dos preços dos imóveis, com destaque para os imóveis já prontos. Ao longo do período sob análise, Bezerra et al (2013) observaram que a variação dos preços dos imóveis foi marcante. Em geral, a variação dos preços superou o custo da construção e a inflação medida no período. Deve-se destacar que após 2008, mesmo com a eclosão da crise financeira internacional e a redução no ingresso de capitais estrangeiros no Rio Grande do Norte, o aumento de preços dos imóveis tendeu a superar a elevação do custo da construção civil.

Para avaliar mais precisamente a existência de bolhas, Bezerra et al (2013) construiu indicadores para aferir o comportamento dos preços dos imóveis prontos (preço spot) e dos vendidos na planta (preço forward), dos aluguéis, além de considerar a evolução do custo da construção civil na cidade e da Taxa Selic ${ }^{13}$, utilizada como taxa de juros de referência.

Os indicadores compreenderam o período 2005-2010, tendo sido calculados por bairros selecionados, que se destacaram tanto pelo número de empreendimentos imobiliários lançados, quanto por estarem "associados a algum fator de atração especial, como por exemplo a infra-estrutura turística e de serviços" (BEZERRA et al, 2013, p. 188).

\footnotetext{
${ }^{12} \mathrm{Em}$ se tratando do estado do Rio Grande do Norte, a taxa de crescimento da modalidade crédito habitacional no período $2008-2010$ foi de cerca de $260 \%$.

${ }^{13}$ Taxa básica de juros da economia, utilizada como referência pela política monetária.
} 
Os indicadores considerados foram:

Indicador de preço dos imóveis (IP):

$$
I P=\frac{(\text { preço imóvel pronto }- \text { preço imóvel planta })}{\text { preço imóvel planta }}
$$

Esse indicador de preço IP, inspirado em Davidson (1978/1982), foi comparado à taxa de juros (tal como sugere a abordagem dessa questão à luz do capítulo 17 da Teoria Geral). Assim, as empresas de construção civil comparariam o diferencial dado pelo IP com a taxa de juros de referência (no caso a SELIC), para avaliar se compensava vender o imóvel na planta ou pronto. Os autores consideravam que o diferencial de preço a favor do imóvel pronto era um indicador da atratividade das novas construções e quanto maior fosse essa diferença, maior seria o indício de ocorrência de movimentos especulativos.

O indicador IP para a cidade de Natal, e por bairros selecionados, bem como a taxa Selic no período investigado são apresentados na tabela abaixo.

Tabela 1 - Indicador IP e taxa Selic

\begin{tabular}{cccccccc}
\hline IP & Natal & Candelária & $\begin{array}{c}\text { Capim } \\
\text { Macio }\end{array}$ & Lagoa Nova & $\begin{array}{c}\text { Ponta } \\
\text { Negra }\end{array}$ & Tirol & Taxa Selic \\
\hline 2005 & $-0,101$ & n/d & 0,187 & 0,120 & 0,209 & $-0,225$ & 0,191 \\
2006 & 0,180 & 0,125 & 0,188 & 0,061 & 0,116 & 0,058 & 0,153 \\
2007 & 0,159 & 0,476 & 0,007 & 0,078 & 0,313 & 0,072 & 0,120 \\
2008 & 0,218 & 0,135 & 0,107 & 0,212 & 0,085 & $-0,106$ & 0,124 \\
2009 & $-0,174$ & n/d & $-0,177$ & $-0,257$ & $-0,311$ & 0,231 & 0,097 \\
2010 & $-0,161$ & n/d & $-0,207$ & $-0,126$ & $-0,375$ & 0,064 & 0,098 \\
\hline
\end{tabular}

Fonte: Bezerra et all (2013). Nd: dados insuficientes para construir indicador significativo para este ano.

Bezerra et al (2013, p. 189), conforme exposto, consideram que os "valores do indicador IP positivos indicam potencial atrativo para novas construções". Tomando por base a tabela 1, os autores constatam que nos anos 2005-2008, "enquanto a taxa SELIC manteve tendência de queda no período, o indicador IP evoluiu ascendentemente tanto para o total da cidade como para a maioria dos bairros". Os autores chamam atenção para os casos dos bairros de Ponta Negra e Capim Macio, 
que no primeiro ano da série operavam como atratores de novas construções devido, provavelmente, ao fato do movimento especulativo ter se iniciado nos mesmos.

Para a cidade de Natal, no período 2006-2008, os autores observaram um aumento na atratividade de novos empreendimentos imobiliários em grande parte de seus bairros, em decorrência da elevação dos preços dos imóveis. Embora a valorização imobiliária tenha começado nos bairros de Ponta Negra e Capim Macio, conforme assinalado, não ficou restrita aos mesmos, incorporando outros bairros nessa dinâmica, o que resultou em um crescente processo de verticalização da cidade.

Após 2008 ocorre um fenômeno inverso, com o indicador IP tornando-se negativo na maioria dos bairros considerados e em Natal. Esta situação, que também se reproduz em 2010, reflete a valorização dos imóveis na planta comparativamente aos imóveis prontos, ou seja, ambos os preços mantiveram suas respectivas trajetórias de crescimento, mas há uma mudança na estrutura de preços relativos, pois o preço forward aumenta mais que o preço spot. A taxa Selic, por sua vez, manteve seu movimento descendente.

Outro indicador elaborado por Bezerra et al (2013) para captar o movimento de formação de bolhas nos preços dos imóveis comparava a evolução do valor dos aluguéis com a trajetória dos preços dos imóveis na cidade ${ }^{14}$. Uma queda no valor desse índice ao longo do período estudado, denominado IA, indicaria uma tendência de valorização dos preços desses ativos.

O referido indicador, segundo os autores, deveria ser contraposto ao comportamento da taxa de juros. Assim, se a queda dos juros fosse menor que as reduções observadas em IA se estaria diante uma situação que poderia ser caracterizada como um movimento especulativo. E se o declínio deste indicador fosse muito pronunciado poderia constituir uma evidência da ocorrência de uma bolha imobiliária.

\footnotetext{
${ }^{14} \mathrm{Em}$ condições de operação do mercado imobiliário normais, o valor dos aluguéis tende a ser uma fração constante do preço dos imóveis. Na eventual presença de bolhas especulativas, o preço dos imóveis tende a aumentar mais que proporcionalmente, quando comparado ao aluguel, causando redução no valor do índice IA, que é dado pela razão aluguel/ preço do imóvel pronto.
} 
Bezerra et al (2013) constataram que o valor do aluguel como proporção do preço do imóvel em Natal passou de 0,61\% em 2005 para 0,35\% em 2007, refletindo o declínio que ocorreu na maioria dos bairros. Contudo, após 2008, o IA voltou a subir, mantendo uma proporção acima de 0,45\% até 2010. De modo geral, comparando-se a evolução do indicador com o comportamento da taxa Selic no período, verifica-se que a queda em IA é mais acentuada. Dessa forma, pode-se dizer que o indicador IA confirma o resultado captado pelo indicador IP.

\section{BOLHA IMOBILIÁRIA COMO SITUAÇÕES DE BACWARDATION E DE CONTANGO}

Os indicadores sistematizados acima sugerem a existência de uma bolha no mercado imobiliário de Natal no período 2005-2007, que à luz da abordagem de Davidson (1978/1982) poderia ser classificada como uma situação de backwardatin, caracterizada por um estímulo exacerbado aos novos lançamentos imobiliários na cidade. Todavia, os dados revelam mudanças nessa dinâmica após 2008, ainda que a mesma não se dê de forma abrupta.

Convém examinar o setor imobiliário na cidade de Natal, no período 2009-2010, que introduz mudanças nesse quadro de análise: os dados acerca da procedência de turistas para a cidade mostram redução do número de estrangeiros que visitaram-na após a crise de 2008, e, conforme já observado, do fluxo de capital externo dirigido à compra de imóveis. Mas a queda no número de turistas estrangeiros foi compensada pelo aumento do número de visitantes de brasileiros procedentes de outros estados/regiões do país. Ademais, a expansão do crédito habitacional após 2008 parece ser uma das causas explicativas para a manutenção do crescimento dos preços dos imóveis locais, a despeito da redução do influxo de capital estrangeiro para a aquisição de ativos imobiliários, bem como para a continuidade de lançamento de novos empreendimentos na cidade, inclusive com a entrada de incorporadoras que atuavam em outros centros no Brasil.

Todavia, como observam Bezerra at al (2013),

há alguns aspectos que precisam ser considerados: o indicador de preço dos imóveis (IP), que em 2008 atingiu o pico de 0,218, em 2009 e 2010 tornou-se negativo, - 0,174 e - 0,161 , respectivamente. A mudança de preços relativos que 
responde pela redução desse indicador nesses dois últimos anos, se não sinaliza uma queda de demanda, já que tanto o preço forward (preço do imóvel na planta) quanto o preço spot (preço do imóvel pronto) continuaram a subir, parece indicar um arrefecimento no ritmo de incremento dos preços. Bezerra at al (2013, p. 194)

Conforme aponta o aludido trabalho, o preço spot responderia à variação da demanda, considerando que, neste mercado, a curva de oferta preço-inelástica incluiria apenas os estoques de imóveis disponíveis, produzidos em períodos anteriores. Por outro lado, o preço forward teria por base uma função de oferta preço-elástica, Davidson (1978/1982, p. 88). No caso típico da construção civil, esse preço consistiria de um mark up estabelecido sobre o custo de construção.

Convém observar que, neste período, os indicadores econômicos mantiveram bom desempenho, especialmente se considerarmos os níveis de emprego e de renda, bem como de expansão do crédito imobiliário.

As especificidades que marcariam a alteração da estrutura de preços relativos no último biênio da série não seriam típicas das situações de contango descritas por Davidson, em que os preços spot ao caírem abaixo do preço forward expressariam tipicamente uma redundância de ativos.

Davidson explora duas situações de contango nas quais existem redundância de capital. Na situação de contango tipo I, o preço spot cai abaixo do preço forward, embora permaneça acima do preço mínimo que induziria nova produção do ativo, caracterizando um estado de redundância relativa. Enquanto a situação de contango tipo II, a queda no preço spot é tão ampla que o mesmo cai abaixo do referido preço mínimo.

Considerando que ambos os preços, spot e forward, sobem em ritmos diferentes, a explicação plausível parece ser que aumento do custo da construção civil foi mais intenso que o incremento da demanda. A evolução do indicador de preço e custo da construção (IC) $)^{15}$ no quadro abaixo parece sustentar essa perspectiva.

\footnotetext{
${ }^{15} \mathrm{IC}$ = preço dos imóveis/ custo da construção civil.
} 


\begin{tabular}{|} 
Quadro 1 - Indicador IC \\
\hline IC & \\
\hline 2005 & NATAL \\
2006 & 4,1 \\
2007 & 4,4 \\
2008 & 4,7 \\
2009 & 5,1 \\
2010 & 3,7 \\
\hline
\end{tabular}

Fonte: Elaboração própria

Após 2008, o indicador IC atinge seu menor valor em 2009, 3,7, e em 2010 encontra-se praticamente no mesmo patamar do ano de 2005, 4,0. A elevação do preço forward em um ritmo superior ao preço spot parece indicar que no caso dessa situação de contango, o aumento nos custos de construção foi superior ao incremento do preço dos imóveis prontos. Este quadro deve ter sido resultado da incorporação de apartamentos recém construídos ao estoque de imóveis da cidade, o que certamente não foi compensado pelo crescimento da demanda por esses ativos na intensidade necessária para evitar tal situação.

Conforme já ressaltado, os casos de contango descritos por Davidson caracterizam tipicamente situações de redundância de ativos. Mas, curiosamente, no mercado imobiliário de Natal entre 2009-2010, há construções de novos apartamentos, ou seja, produção de novos ativos. Assim, embora a redundãncia deva ser qualificada como relativa, conforme apontado por Bezerra at al (2013), não se enquadra nos casos abordados por Davidson em seus trabalhos, ao contrário do que sugerido no aludido trabalho.

Desse modo, o indicador IP mostrou no biênio 2009-2010 um comportamento que, em última análise, poderia caracterizar um ponto de inflexão, em que o mercado imobiliário já não se encontrava mais em posição de backwardation, mas tampouco atingira as posições de contango I e II, com o segundo tipo expressando claramente um quadro de colapso no setor, em que já não valeria mais a pena produzir novos apartamentos. Enfim, seria uma situação de desestímulo à produção.

\section{CONSIDERAÇÕES FINAIS}

O fenômeno de bolha imobiliária aqui tratado permitiu identificar um tipo de contango diferente, em que ambos os preços spot e forward sobem. Nesse sentido, 
parece razoável supor que, de forma geral, uma abordagem de bolha de ativos à luz da teoria de Davidson ao incorporar essa nova forma de contango pode fornecer indicações acerca da formação de uma bolha e de sua transição em direção ao seu arrefecimento. Ela constituiria um ponto de inflexão entre a situação de backwardation e dos tipos de contango I e II descritos por Davidson.

Como exploração preliminar dessa questão, considera-se que esse tipo de contango serveria ao tratamento de um ciclo imobiliário, com a situação de backwardation correspondendo à fase ascendente do ciclo, enquanto a situação de contango diferente aqui tratada, observada no biênio 2009-2010, constituiria uma situação de reversão em direção à trajetória descendente. As situações de contango I e contango II, respectivamente, descreveriam a fase de descenso, com o segundo tipo indicando uma aproximação de seu vale.

\section{REFERÊNCIAS BIBLIOGRÁFICAS}

ANDERSON, P., Arrow, K. e Pines, D. (orgs) The economy is an evolving complex system. Redwood city: Addison Wesley, 1988.

BLACK, J. Oxford Dictionary of Economics. Oxford University Press, 1997.

BLANCHARD, O.J. \& Fischer, S. Lectures in Macroeconomics. Nova lorque: MIT Press, 1989.

CANUTO, O. e Laplane, M. Especulação e instabilidade na globalização financeira. Economia e Sociedade, Campinas, n.5, p.31-60, dez. 1995

CARVALHO, F.J.C. "Sobre a preferência pela liquidez dos bancos" In: Amado, A. [et al] Sistema financeiro: uma análise do setor bancário brasileiro: Elsevier, 2007. Sobre a centralidade da teoria da preferência pela liquidez na macroeconomia pós-keynesiana. Ensaios FEE, Porto Alegre (17)2:42-77, 1996.

COUTINHO, L. M. e Nascimento M.M. Crédito habitacional acelera o investimento habitacional no país. In Torres Filho, E.T.; Puga, F.P.; Ferreira, F.M.R (orgs). Visão do desenvolvimento. Rio de Janeiro: BNDES, 2006.

DAVIDSON, P. Money, Portfolio Balance, Capital Accumulation, and Economic Growth. Econometrica, Vol. 36, No. 2. (Apr. 1968), pp. 291-321. 
Money and the real world. Basingstoke: MacMillan, 1972. $2^{\mathrm{a}}$ edição,

1978.

Post Keynesian Macroeconomic Theory: A Foundation for Sucessful Economic Policies for the Twenty-firts Century. Aldershot: Edward Elgar, 1994.

DYMSKI, G.A. "Economia de bolha" e crise financeira no leste asiático e na Califórnia: uma perspectiva espacializada de Minsky". In: Economia e Sociedade, no. 11, dez. 1998.

"Bolhas de ativos e crises em Minsky: uma abordagem espacializada" In:

Globalização financeira: ensaios de macroeconomia aberta. Ferrari Filho, F. e Paula, L.F (orgs). Petrópolis, RJ: Vozes, 2004.

FERREIRA, A. L. [et al] Dinâmica imobiliária, turismo e meio ambiente: novos cenários metropolitanos IN: Clementino, M. L.M. e Zoraide, P (orgs). Natal, uma metrópole em formação. Educ, 2009.

Jornal Tribuna do Norte, 28/01/2007

Jornal Tribuna do Norte, 23/08/2008

HAUGEN, R.A. The Inefficient stock market. Nova Jersey : prentice-hall, 1999.

HICKS, J.R. Value and Capital. Oxford: Oxford University Press, 1939.

KEYNES, J.M. (1936) A Teoria Geral do Emprego, do Juro e da Moeda. Coleção Os Economistas. São Paulo: Abril Cultural, 1982.

KINDLEBERGER, C. P. Manias, panics and crashes: a history of financial crises. New York, Basic Books, 1978. Edição revisada, 1989. Tradução para português: Manias, pânico e crashes: um histórico das crises financeiras. Rio de Janeiro: Nova Fronteira, 2000.

MACEDO e SILVA, A.C. A montanha em movimento: uma notícia sobre as transformações recentes da economia global. In: Carneiro, R. (org) A Supremacia dos mercados e a política econômica do governo Lula. São Paulo: Editora UNESP, 2006.

SP: FECAMP, 1999.

A macroeconomia sem equilíbrio. Petrópolis, RJ: Vozes; Campinas,

MANDELBROT, B.B. "Fractals and scaling in finance: discontinuity, concentration, risk": Springer Verlag New York (1997)

MILES, D. \& Scott, A. Macroeconomia: compreendendo a riqueza das nações. Editora Saraiva, 2005. 
OREIRO, J.L Bolhas, incerteza e fragilidade financeira In: Globalização financeira: ensaios de macroeconomia aberta. Ferrari Filho, F. e Paula, L.F (orgs). Petrópolis, RJ: Vozes, 2004.

OBSERVATÓRIO DAS METRÓPOLES - NÚCLEO NATAL. "Estudo comparativo sobre o papel das atividades imobiliária-turísticas na transformação do espaço social das metrópoles nordestinas: Salvador, Recife, Natal e Fortaleza". Natal, UFRN, 2009 - Relatório de Pesquisa (preliminar).

RIBEIRO, L.C.Q. Dos Cortiços aos Condomínios Fechados: as formas de produção da moradia na cidade do Rio de Janeiro. Rio de Janeiro: Civilização Brasileira e Ippur (UFRJ), 1997.

SANTOS, H.L. A Atividade turística e o setor imobiliário: influxoss de riqueza e trabalho em Natal (monografia). UFRN, Natal, 2007.

SECRETARIA DE TURISMO DO RIO GRANDE DO NORTE: indicadores básicos de turismo. Natal, 2007.

TOBIN, J. A General Equilibrium Approach to Monetary Theory, Journal of Money, Credit and Banking, 1: 15-29, 1969.

VIDOTTO, C. O espectro de Keynes ronda a América: hipotecas, securitização e crise financeira nos Estados Unidos. In: Sicsú, J. e Vidotto, C. (orgs) Economia do Desenvolvimento. Rio de Janeiro: Elsevier, 2008. 